\title{
The 1985 Southern Hemisphere mid-latitude total column ozone anomaly
}

\author{
G. E. Bodeker ${ }^{1}$, H. Garny ${ }^{2}$, D. Smale ${ }^{1}$, M. Dameris ${ }^{3}$, and R. Deckert ${ }^{3}$ \\ ${ }^{1}$ National Institute of Water and Atmospheric Research, Lauder, New Zealand \\ ${ }^{2}$ Meteorological Institute, University of Munich, Munich, Germany \\ ${ }^{3}$ DLR-Institut für Physik der Atmosphäre, Oberpfaffenhofen, Germany
}

Received: 5 April 2007 - Published in Atmos. Chem. Phys. Discuss.: 14 May 2007

Revised: 31 August 2007 - Accepted: 10 September 2007 - Published: 14 November 2007

\begin{abstract}
One of the most significant events in the evolution of the ozone layer over southern mid-latitudes since the late 1970s was the large decrease observed in 1985. This event remains unexplained and a detailed investigation of the mechanisms responsible for the event has not previously been undertaken. In this study, the 1985 Southern Hemisphere mid-latitude total column ozone anomaly is analyzed in detail based on observed daily total column ozone fields, stratospheric dynamical fields, and calculated diagnostics of stratospheric mixing. The 1985 anomaly appears to result from a combination of (i) an anomaly in the meridional circulation resulting from the westerly phase of the equatorial quasi-biennial oscillation (QBO), (ii) weaker transport of ozone from its tropical mid-stratosphere source across the sub-tropical barrier to mid-latitudes related to the particular phasing of the QBO with respect to the annual cycle, and (iii) a solar cycle induced reduction in ozone. Similar QBO and solar cycle influences prevailed in 1997 and 2006 when again total column ozone was found to be suppressed over southern mid-latitudes. The results based on observations are compared and contrasted with analyses of ozone and dynamical fields from the ECHAM4.L39(DLR)/CHEM coupled chemistry-climate model (hereafter referred to as E39C). Equatorial winds in the E39C model are nudged towards observed winds between $10^{\circ} \mathrm{S}$ and $10^{\circ} \mathrm{N}$ and the ability of this model to produce an ozone anomaly in 1985, similar to that observed, confirms the role of the QBO in effecting the anomaly.
\end{abstract}

\section{Introduction}

Total column ozone over southern mid-latitudes has decreased since the early 1980 's. However, this decrease has

Correspondence to: G. E. Bodeker

(g.bodeker@niwa.co.nz) not occurred as a purely monotonic decline but rather as a number of stepwise decreases superimposed on a background linear decline. Perhaps the largest of these stepwise decreases occurred in 1985 when total column ozone over southern mid-latitudes decreased by up to 30 Dobson Units (DU; $1 \mathrm{DU}=2.69 \times 10^{16}$ molecules $/ \mathrm{cm}^{2}$ ) depending on location. This feature has been commented on in a number of previous studies (e.g. Bodeker et al., 2001) but cannot be tracked by many state-of-the-art chemistry-transport models and remains largely unexplained (Chapter 3 in WMO, 2007).

Potential explanations for the 1985 ozone anomaly are:

1. In situ depletion of ozone over southern mid-latitudes.

2. Export of ozone depleted air from Antarctica.

3. A reduction in mid-latitude ozone due to a $\mathrm{QBO}$ induced change in the strength of the meridional circulation (Baldwin et al., 2001).

4. Anomalously weak transport of ozone from its tropical source, across the subtropical barrier, to mid-latitudes. This could result from unforced inter-annual variability in the frequency of mixing events or from the QBO itself (thereby creating a second order dependence on the QBO).

5. Reduced mid-latitude ozone concentrations due to a minimum in the solar cycle.

A combination of these processes may also be possible. While the El Niño Southern Oscillation (ENSO) is known to drive changes in total column ozone in the Southern Hemisphere in winter (Randel and Cobb, 1994), the Southern Oscillation Index (the normalized Tahiti minus Darwin sealevel pressure) was close to zero through 1984, 1985 and 1986. Therefore we have not considered ENSO as a potential explanatory factor for the 1985 ozone anomaly. The first option is highly unlikely as there are no documented sudden and

Published by Copernicus Publications on behalf of the European Geosciences Union. 


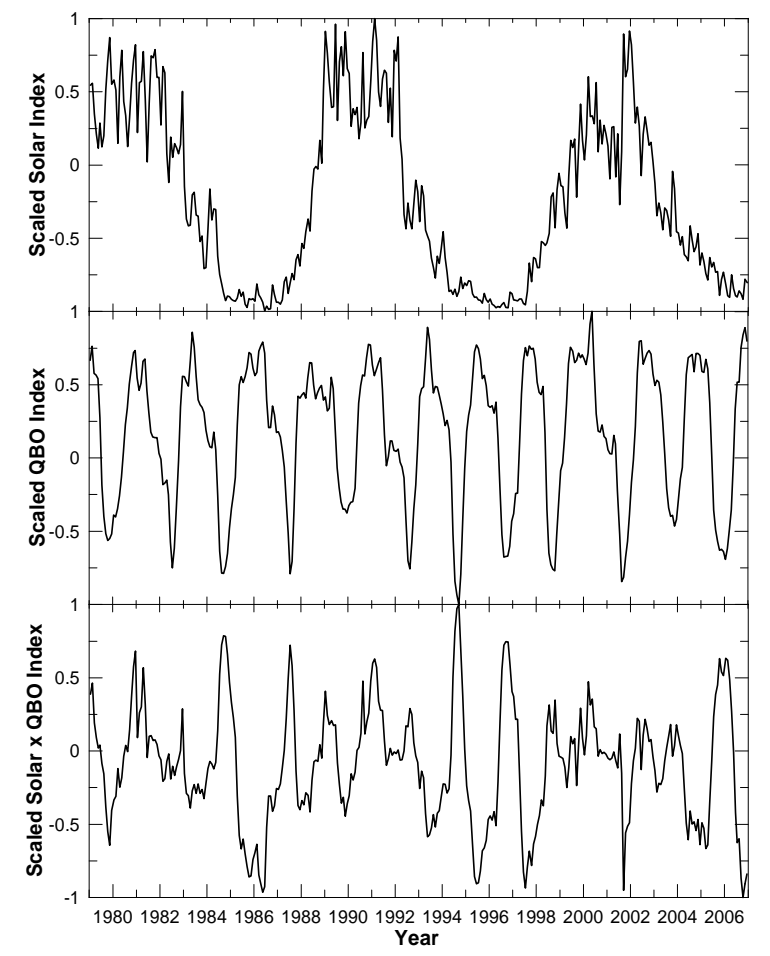

Fig. 1. Upper panel: a dimensionless solar cycle activity index (scaled from -1 to +1 ) based on daily $10.7 \mathrm{~cm}$ solar flux measurements made at Ottawa from January 1960 to May 1991 and at Penticton from June 1991 to the present. On time scales longer than one month, the $10.7 \mathrm{~cm}$ solar flux has been found to correlate well with solar ultraviolet radiation variations at stratospherically important wavelengths (Donnelly, 1991). Middle panel: a dimensionless index scaled from -1 (easterly) to +1 (westerly) for the QBO based on $50 \mathrm{hPa}$ equatorial zonal mean zonal winds. Bottom panel: the product of the QBO and solar cycle indices scaled to -1 to +1 .

rapid increases in ozone depleting substance concentrations nor of rapid changes in southern mid-latitude stratospheric chemistry over this period.

With regard to option 2, the vortex period averaged ozone mass deficit over Antarctica in 1985 was approximately 2.5 times larger than in $1984\left(4.63 \times 10^{9} \mathrm{~kg}\right.$ in 1985 cf. $1.85 \times 10^{9} \mathrm{~kg}$ in 1984 ) and greater than any previous year (Huck et al., 2005). While it is unlikely that this ozone depleted air over Antarctica would have affected mid-latitudes much before the breakdown of the polar vortex, if there was considerable diabatic descent inside the vortex during this period, air depleted in ozone may have been transported down into the lowermost stratosphere, below the base of the vortex. Transport along isentropic surfaces could have advected the descended anomaly out to mid-latitudes. However, previous analysis of total column ozone anomalies (see Fig. 6b of Kinnersley and Tung, 1998) shows that the anomaly appears in the first half of 1985 at sub-tropical latitudes and then propagates poleward, reaching the Antarc- tic in October/November of that year. This suggests that the anomalously large Antarctic ozone depletion in 1985 was caused in part by an equatorial anomaly advected poleward rather than the polar ozone depletion being the driver of the mid-latitude anomaly.

Kinnersley and Tung (1998) showed that by forcing an interactive chemical-dynamical model of the stratosphere with observed Singapore zonal winds and with the observed daily varying planetary wave heights just above the tropopause, much of the observed interannual variability in monthly mean total column ozone globally could be reproduced. Similar to the approach used in the E39C model (see Sect. 2), the zonal winds between 10 and $70 \mathrm{hPa}$ and between $10^{\circ} \mathrm{S}$ and $10^{\circ} \mathrm{N}$ were relaxed towards the observed Singapore winds with a time constant of 1 day. The best correlations were found within $50^{\circ}$ of the equator during winter and autumn in both hemispheres (the period when wave induced transport of ozone from the tropics to higher latitudes is greatest), suggesting that the fourth possibility listed above might be more likely. In this model, the propagation of the ozone anomaly from equatorial to higher latitudes occurred only in the Southern Hemisphere. However, Kinnersley and Tung (1998) did not use observed planetary wave amplitudes in the Southern Hemisphere but rather a repeating annual (July 1980 to June 1981) cycle of wave amplitudes since "use of the observed interannually varying waves gave unrealistic results". Therefore, any planetary wave induced equator to pole advection anomaly in 1985 would not be faithfully reproduced in their model. Furthermore, Kinnersley and Tung (1999) showed that the mid-latitude QBO signal in ozone results primarily from the direct QBO modulation of the meridional circulation and, to a lesser extent, QBO modulation of mid-latitude planetary wave activity. As opposed to Gray and Pyle (1989), who modelled the extra-tropical QBO signal in ozone as a poleward advection and diffusion of the QBO induced tropical ozone anomaly, Kinnersley and Tung (1999) found that diffusion by planetary waves actually reduces the mid-latitude ozone anomaly by spreading it to lower and high latitudes. That said, reduced diffusion by planetary waves and/or reduced transport of ozone from its tropical source region to mid-latitudes, would exacerbate the anomaly as the smoothing effects of the mixing would be reduced. Using Lyapunov exponents as a measure of mixing, Bowman (1993) showed anomalously weak mixing between the tropics and southern mid-latitudes in 1985.

Kinnersley and Tung (1998) proposed a positive feedback that would amplify negative ozone anomalies caused by the QBO i.e. if the Antarctic stratosphere is colder than usual due to the QBO (Lait et al., 1989) ozone depletion will be enhanced as a result of greater polar stratospheric cloud formation. Reduced ozone will reduce solar heating which will strengthen the circumpolar vortex, decrease planetary wave activity, and so reduce mixing of ozone from lower latitudes and further reduce ozone levels. It should be noted that ozone responds not only to the secondary circulation associated 
with the QBO but also to the temperature variations because of the strong dependence of chemical loss rates on temperature (Lee and Smith, 2003). This suggests that the third and fourth possibilities listed above, working in tandem, and possibly with ozone levels further reduced by a minimum in the solar cycle (McCormack and Hood, 1996; Soukharev and Hood, 2006), could explain the 1985 mid-latitude anomaly. It is interesting to note that the product of a $50 \mathrm{hPa} \mathrm{QBO}$ signal and a solar activity index (Fig. 1) shows anomalously low values through most of 1985/1986, as well as 1995, 1997, 2001 and 2006 (which also showed anomalously low southern mid-latitude ozone, see Sect. 3.1). While no geophysical mechanism can be ascribed to the product of the QBO and solar cycle signals, such a term would represent any solar cycle influence on the QBO effect on ozone and/or any QBO influence on the solar cycle effect on ozone i.e. second order effects whereby the influence of the solar cycle on ozone depends on the phase of the QBO (and vice versa).

\section{The E39C model}

A full description of the E39C model is provided in Dameris et al. (2005) and Dameris et al. (2006). The features of the model relevant to this study are summarized in this section. The model has a horizontal resolution of T30, with 39 layers from the surface to an upper layer centered at $10 \mathrm{hPa}$. Heating and photolysis rates are sensitive to the three-dimensional distributions of the radiatively active gases $\left(\mathrm{O}_{3}, \mathrm{CH}_{4}, \mathrm{~N}_{2} \mathrm{O}, \mathrm{H}_{2} \mathrm{O}\right.$, and CFCs), and clouds, so that changes in atmospheric composition affect atmospheric temperatures and hence transport. Observed sea surface temperatures and sea ice cover (update of Rayner et al., 2003), and observed greenhouse gases and CFC concentrations (Chapter 6 in WMO, 2007), provide the model boundary conditions. The 11-year solar cycle affects both heating rates and photolysis rates of chemical species. The impact of solar activity changes on short-wave heating rates is prescribed in two spectral intervals by varying the solar constant. Continuum scattering, grey absorption, water vapor and uniformly mixed gas transmission functions and ozone transmission are all considered (Dameris et al., 2005). The effects of changes in solar activity on photolysis rates are parameterized in 8 spectral intervals (between 178.8 and $752.5 \mathrm{~nm}$ ) according to $10.7 \mathrm{~cm}$ solar flux measurements (see Fig. 1). The spectral distribution of changes in extra-terrestrial solar flux is based on Lean et al. (1997). The effects of solar activity at altitudes above $30 \mathrm{~km}$ are accounted for by prescribing changes in total nitrogen, obtained from a transient simulation of a 2-D model (Brühl and Crutzen, 1993), as a model upper boundary condition. The QBO is forced by linear relaxation of the equatorial zonal winds in the lower stratosphere toward observed zonal wind profiles. The effects of past major volcanic eruptions

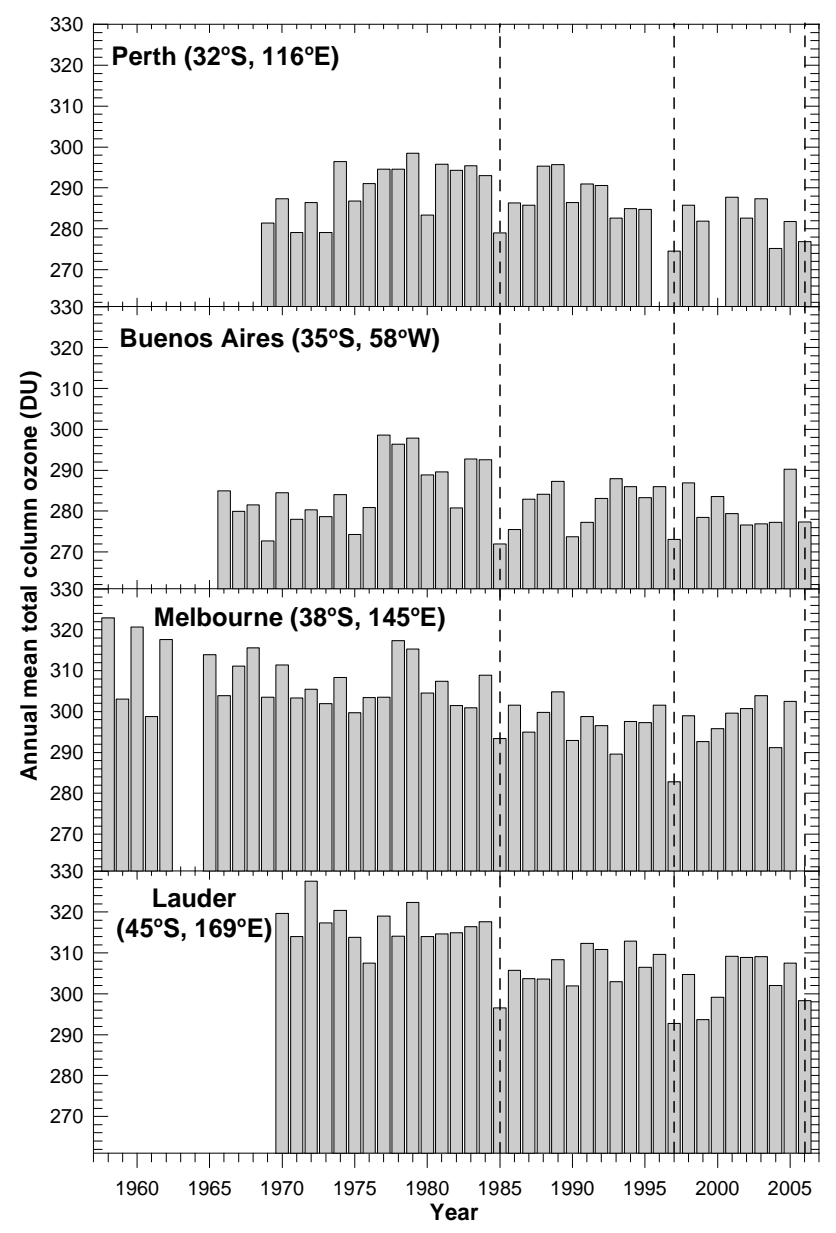

Fig. 2. Annual mean total column ozone measured at 4 southern mid-latitudes sites. The vertical dashed lines shows the years of 1985, 1997 and 2006.

(Agung in 1963; El Chichón in 1982; and Pinatubo in 1991) are also included.

\section{The evidence}

\subsection{Temporal and spatial pattern of the anomaly}

The temporal context of the 1985 anomaly is shown in Fig. 2 where long-term annual mean time series of total column ozone from 4 locations are plotted. The annual means at the 4 sites were calculated from Dobson spectrophotometer measurements obtained from the World Ozone and UV Data Center (WOUDC), requiring 5 daily values for a monthly mean to be valid, at least 8 monthly means for an annual mean to be valid, and with corrections based on a monthly mean climatology to correct for temporal seasonal biasing in these calculations. Missing values result from these criteria not being met (e.g. there were insufficient data to calculate a value for Melbourne in 2006). These long-term time series show 


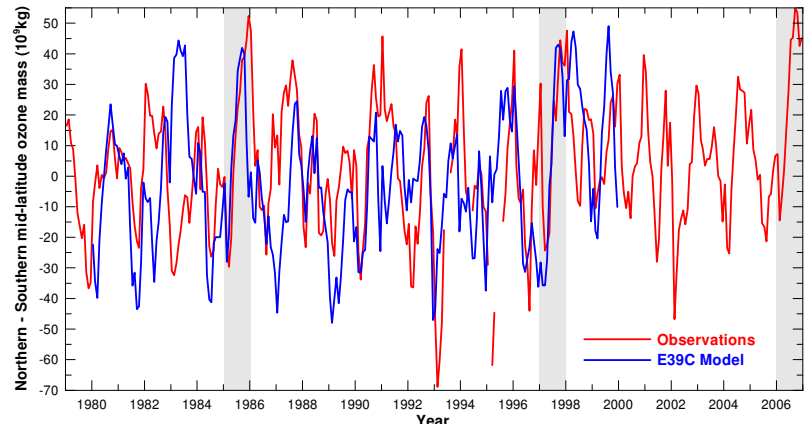

Fig. 3. Northern minus southern mid-latitude $\left(30^{\circ}-60^{\circ}\right)$ deseasonalised monthly mean ozone mass time series based on the NIWA combined total column ozone data base (red) and output from the E39C model (blue). The years of 1985, 1997, and 2006 are indicated by vertical grey bars.

that the 1985 anomaly represents one of the largest year-toyear changes in annual mean ozone on record and is a key characteristic of long-term changes in ozone over southern mid-latitudes. 1997 also shows very low annual mean total column ozone at all 4 sites and this feature has been discussed by Connor et al. (1999). Annual means in 2006 at three of the locations are also somewhat suppressed.

An earlier analysis of changes in mid-latitude ozone mass indicated that the reductions in southern mid-latitude ozone in 1985 and 1997 were accompanied by increases in ozone over northern mid-latitudes (see Fig. 5 of Bodeker et al., 2001). The ozone mass time series plotted in Bodeker et al. (2001) have been updated and differences between deseasonalised mid-latitude $\left(30^{\circ}-60^{\circ}\right)$ ozone mass values have been calculated based on both the NIWA combined total column ozone data base (Bodeker et al., 2005) and output from the E39C run (see Fig. 3). The years of 1985, 1997 and 2006 are characterized by large increases in the differences between northern and southern mid-latitude ozone mass anomalies that build through the year (see also Fig. 8 later and associated discussion). At the beginning of the year the southern mid-latitudes have a positive ozone mass anomaly with respect to the northern mid-latitudes but by the end of the year the situation is reversed. This seasonal evolution is seen a number of years but it remains a key characteristic of 1985, 1997 and 2006 and is seen in both the observations and in the E39C model output. This bimodal pattern of variability is explored further in Sect. 3.3. To show more clearly the full spatial structure of the 1985 anomaly, Southern Hemisphere seasonal total column ozone anomalies have been calculated. Time series through each of 4 seasons (December to February (DJF), March to May (MAM), June to August(JJA), and September to November (SON)) were regressed against equivalent effective stratospheric chlorine (Daniel et al., 1995) over the period 1980 to 1999 (to remain consistent with the period for which E39C output was

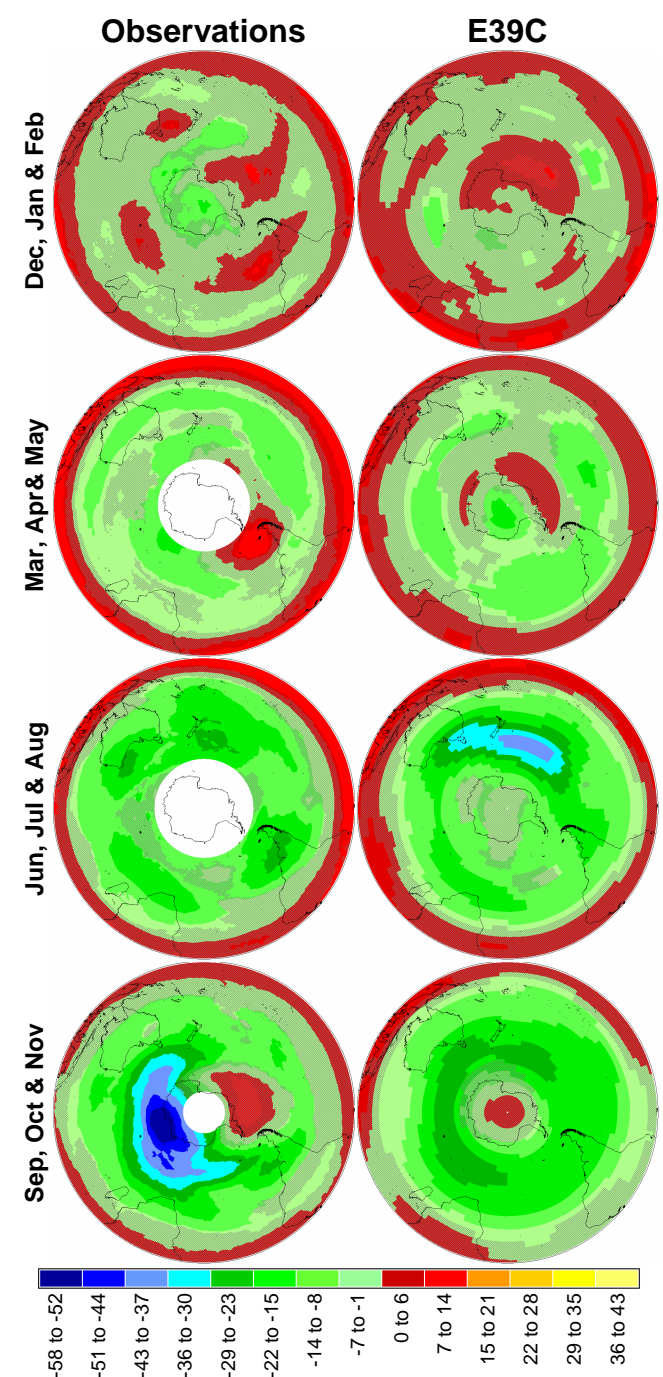

Fig. 4. (Left column) Observed and (right column) modelled seasonal anomalies in Southern Hemisphere total column ozone in 1985 (the December values are from 1984) with respect to the period 1980 to 1999 . The anomalies are calculated by subtracting fits to equivalent effective stratospheric chlorine in each grid cell calculated independently for each season. The colour scale at the bottom shows the total column ozone anomalies in DU. Regions where the anomalies are not statistically significantly different from zero at the $1 \sigma$ level are hatched.

available). Residuals from each regression then represent the ozone anomalies with respect to values expected from halogen chemistry alone. Anomalies for 1985, calculated from total column ozone fields from the NIWA combined data base and from E39C total column ozone fields, are shown in Fig. 4. Regions coloured green and blue show where total column ozone in 1985 was lower than expected from stratospheric halogen loading alone, while regions coloured red and yellow show where total column ozone in 1985 was anomalously high. Regions where the 1985 anomalies are 
within one standard deviation of the anomalies over the 20 year period are hatched. Early in the year both the observed and modelled differences fields are mostly within $1 \sigma$ of the typical variability. From March to May a more coherent pattern becomes apparent with a ring of positive anomalies within $\sim 15^{\circ}$ of the equator, indicative of the influence of the equatorial QBO (Gray and Pyle, 1989), surrounding a large extra-tropical region of predominantly negative anomalies. By the middle of the year (June to August), the midlatitude negative anomalies have intensified with observed ozone in the season being $\sim 25 \mathrm{DU}$ lower than expected. Slightly more negative anomalies, up to $\sim 35 \mathrm{DU}$, are seen in the model fields. At southern mid-latitudes the effect of the solar cycle in this season would be a reduction in total column ozone of about 3 DU (Calisesi and Matthes, 2006) suggesting that the $\mathrm{QBO}$ is responsible for the majority of the observed anomaly. In SON the anomalously large Antarctic ozone hole in 1985, referred to above, becomes apparent in the observations but not in the E39C ozone fields. In both cases however, the large and statistically significant midlatitude negative anomalies remain. The origin of the wave 1 structure in the observed anomalies in SON can be discerned from Fig. 5 where daily $100 \mathrm{hPa}$ geopotential height and temperature fields from the National Centers for Environmental Prediction/National Center for Atmospheric Research (NCEP/NCAR) reanalyses (Kistler et al., 2001) were used to calculate the seasonal mean deviations away from linear regressions over the period 1980 to 1999 . Both anomaly fields show a clear wave 1 pattern where reduced geopotential heights and lower temperatures in 1985 are approximately collocated with the region of reduced ozone. The large dynamical wave 1 in the stratosphere pushes the polar vortex towards the southern Indian Ocean resulting in the large negative ozone anomalies seen in this region in Fig. 4. Further discussion of the interannual variability in southern mid-latitude wave forcing is presented in Sect. 3.5.

\subsection{Changes in the frequency of high and low ozone events}

To show more clearly the changes in ozone that occur each month in 1985 compared to the mean of the 1980s decade, monthly probability distribution functions (PDFs) have been calculated from daily $1.25^{\circ}$ longitude by $1.0^{\circ}$ latitude total column ozone fields from Nimbus 7 TOMS over $30^{\circ} \mathrm{S}$ to $60^{\circ} \mathrm{S}$. The monthly PDFs for 1985 are compared against the 1980-1989 (but excluding 1985) climatological mean PDFs in Fig. 6.

Throughout 1985 it appears that the likelihood of measuring high ozone values decreased rather than the likelihood of lower ozone values increasing. This is particularly apparent in spring (September and October) when, in 1985, ozone values above $450 \mathrm{DU}$ were hardly ever encountered. This suggests that the 1985 anomaly resulted from a reduction in highest ozone values rather than an increase in lowest ozone values. The ozone PDFs calculated from the E39C total col-

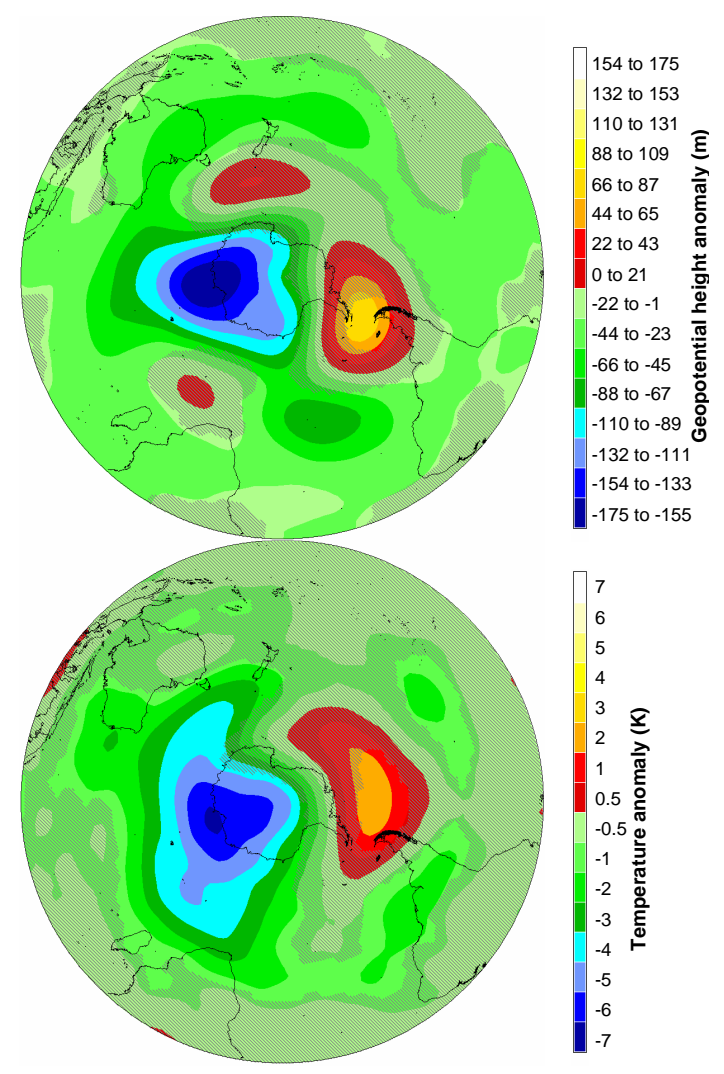

Fig. 5. Anomalies in $100 \mathrm{hPa}$ geopotential heights (top) and $100 \mathrm{hPa}$ temperatures (bottom) over the Southern Hemisphere for September to November 1985. In both cases the anomalies are with respect to linear fits to the data in each grid cell over the period 1980 to 1999 . Hatched regions show where the anomalies are not statistically significantly different from zero at the $1 \sigma$ level.

umn ozone fields are shown in Fig. 7. These too show that the 1985 anomaly is characterized by reductions in the probability of high ozone values rather than increases in the probability of low ozone values. This provides further evidence that it is unlikely that the 1985 anomaly results from export of ozone depleted air from Antarctica since this would have increased the probability of very low ozone values.

\subsection{Inter-hemispheric structure of the anomaly}

Principal component analysis has been used to investigate whether the 1985 southern mid-latitude anomaly is related to any large scale pattern of variability in global ozone. Seasonal mean, zonal mean ( $1^{\circ}$ zones) total column ozone time series were generated from the NIWA combined total column ozone data base. Similar time series were generated from the E39C runs where ozone was interpolated to $1^{\circ}$ resolution. To form anomaly time series with respect to the period before significant ozone depletion began, mean annual cycles calculated from 1980 to 1983 were subtracted from the time series at each latitude. Spatial and temporal modes of 


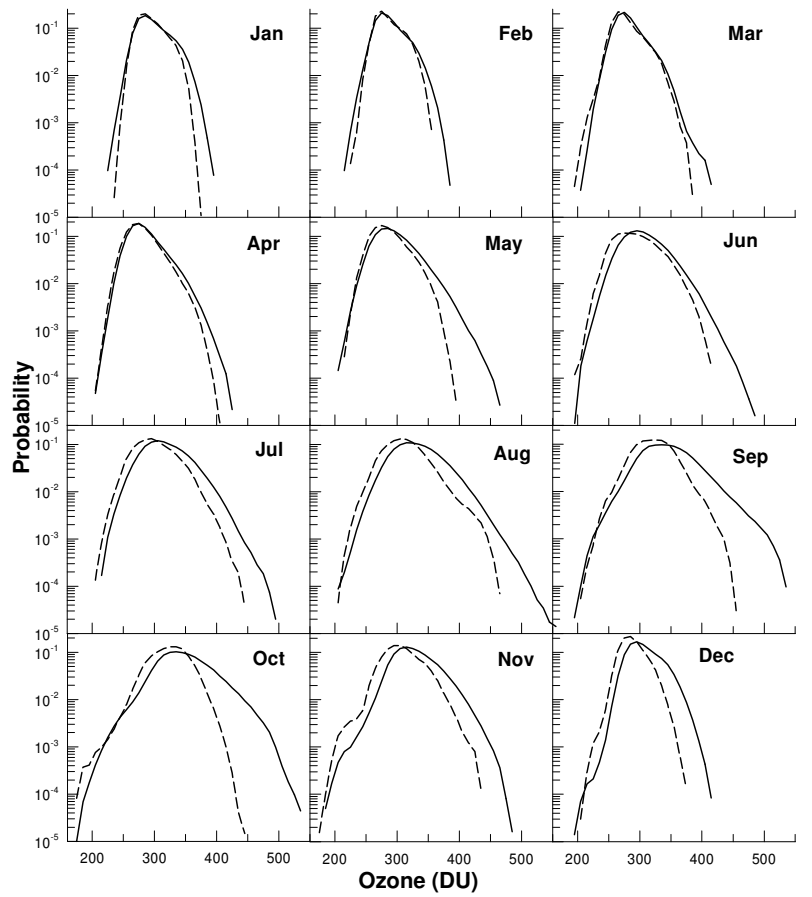

Fig. 6. Monthly probability distribution functions (PDFs) of total column ozone over southern mid-latitudes $\left(30^{\circ} \mathrm{S}\right.$ to $\left.60^{\circ} \mathrm{S}\right)$ for 1985 (dashed lines) compared against the monthly climatological PDFs for the 1980s decade, 1980-1989 but excluding 1985 (solid lines).

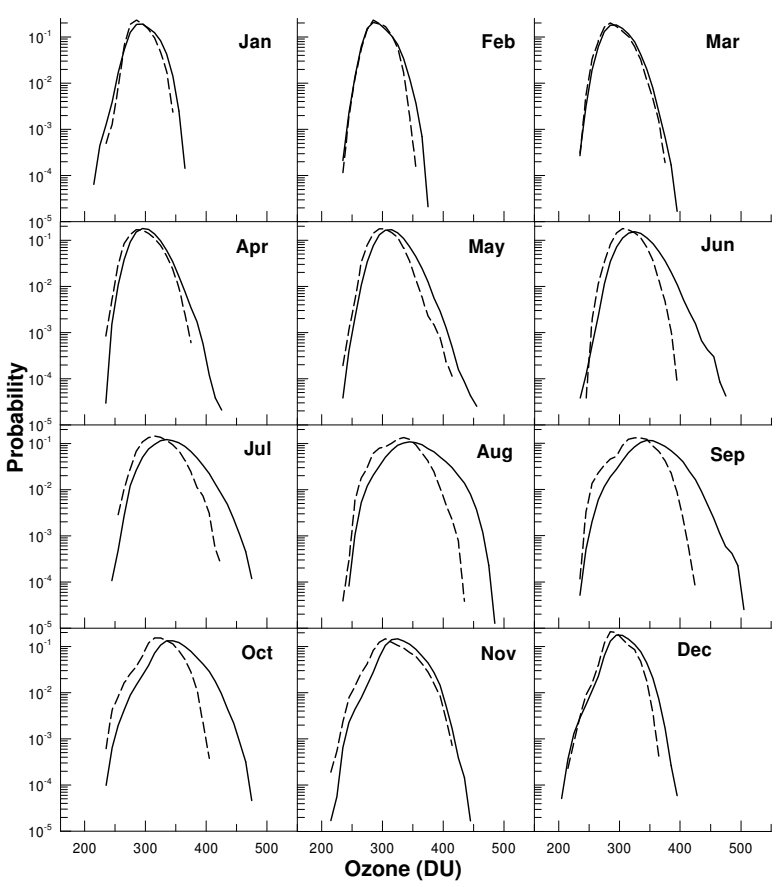

Fig. 7. As for Fig. 6 but calculated from E39C total column ozone fields.

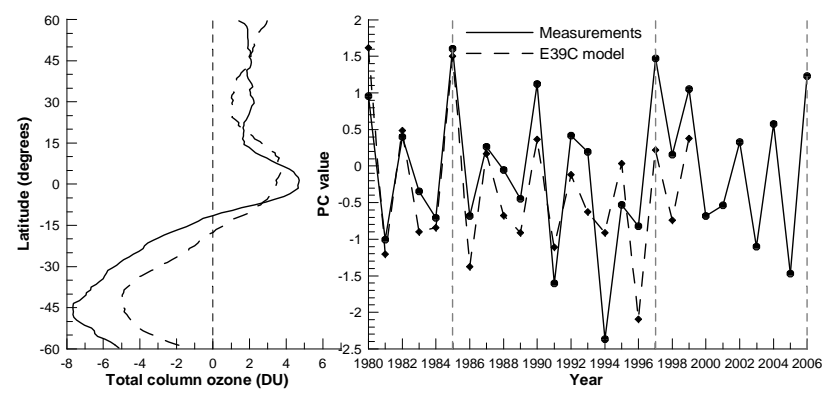

Fig. 8. Left: The 2nd EOF based on measurements (solid line) and model output (dashed line), for the season of September to November. Traces are restricted to $60^{\circ} \mathrm{S}$ to $60^{\circ} \mathrm{N}$ due to data availability. Right: The principal component time series associated with the EOF patterns shown on the left for measurements (solid line with $\bullet$ symbols) and model output (dashed line with filled $\diamond$ symbols). The years of 1985, 1997 and 2006 are shown with grey vertical dashed lines.

variability in the zonal mean anomaly time series were calculated separately for each season by decomposing the area weighted anomaly covariance matrix by principal component analysis (Preisendorfer, 1988). The analysis was performed individually for each season since patterns of variability were expected to be seasonally dependent. The decomposed temporal modes were normalized so that the variance of each temporal mode was 1.0. The normalized temporal modes (principal components; PCs) were projected onto the zonal mean anomalies to generate the spatial modes (empirical orthogonal functions; EOFs). The EOFs were then area deweighted.

For the season of September to November (SON), matching the bottom panel of ozone anomalies displayed in Fig. 2, the first EOF explains 78\% of the variance and describes the long-term trend in ozone in this season. The second EOF, which explains $\sim 6.7 \%$ of the variance, is plotted together with its PC time series in Fig. 8. The PC time series identifies 1985, 1997 and 2006 as anomalous with deviations close to $1.5 \sigma$. The anomaly pattern shows reductions in southern mid-latitude total column ozone in this season, maximizing at $\sim 45^{\circ} \mathrm{S}$, and smaller increases in ozone northward of $\sim 10^{\circ} \mathrm{S}$, particularly over the tropics but extending into northern mid-latitudes.

Similarly, for the E39C model, the first EOF for SON is related to long-term trends in ozone in this season (explaining $\sim 75 \%$ of the variance) while the second EOF, plotted in Fig. 8 together with its PC time series, explains $\sim 13 \%$ of the variance. The E39C PC time series show 1980 and 1985 as anomalous but the EOF pattern of variability is very similar to that observed. The measured and modelled EOF patterns both show negative ozone anomalies in southern midlatitudes and that these negative anomalies occur in conjunction with positive total column ozone anomalies in northern mid-latitudes. This dipole pattern is consistent with the 
mid-latitude ozone mass differences plotted in Fig. 3. Because the hemispheric ozone mass differences appear to accumulate through the year, the principal component analysis results for SON, close to when these differences maximize, show this pattern most clearly.

\subsection{Associated anomalies in stratospheric mixing}

As outlined in Sect. 1, the fourth possible explanation for the 1985 ozone anomaly is an anomaly in the transport of ozone from the tropics to mid-latitudes. Transport is determined by the amount of mixing between the tropics and mid-latitudes which can vary from year to year and therefore change the amount of ozone rich air transported out of the tropics to higher latitudes. To diagnose the degree of mixing over the Southern Hemisphere, Lyapunov exponents were calculated as was done in Bowman (1993). A description of Lyapunov exponents, their use in diagnosing atmospheric mixing, the algorithm for their calculation, and an analysis of uncertainties is presented in detail in Garny et al. (2007). Briefly, Lyapunov exponents measure the separation of two trajectories with time from initially nearby starting points. The exponents are related to the local stretching deformation of the fluid following an air parcel (Bowman, 1993). Divergent velocity fields produce positive Lyapunov exponents, while convergent fields produce negative exponents.

Two dimensional (latitude and longitude) Lagrangian trajectories were computed on isentropic surfaces using a standard 4th order Runge-Kutta integration scheme (Press et al., 1989) applied at $1 \mathrm{~h}$ integration intervals to 6 hourly $2.5^{\circ} \times 2.5^{\circ} \mathrm{NCEP} / \mathrm{NCAR}$ wind fields, and 12 hourly E39C model wind fields, on the 450,550 and $650 \mathrm{~K}$ isentropes. The NCEP/NCAR fields are from the reanalyses (Kalnay et al., 1996) and not from operational forecasts. Trajectories within $20^{\circ}$ of the poles are transformed to a Cartesian coordinate system to avoid the singularity at the pole which occurs when prescribing winds using zonal and meridional components. To determine the mixing between the tropics and mid-latitudes, Lyapunov exponents were calculated for each month from 1980 to 1989 based on 30 day trajectories for both NCEP/NCAR and E39C model wind fields. The starting positions for the trajectories were specified at $2^{\circ}$ longitude spacing and $1^{\circ}$ latitude spacing covering the whole of the Southern Hemisphere. Examples of the calculated trajectories as well as various fields and zonal mean time series of the resultant Lyapunov exponents are shown in Garny et al. (2007). Southern Hemisphere anomalies in monthly Lyapunov exponents (not shown here), calculated by subtracting the mean annual cycle from the time series at each degree of latitude, identify 1985 as having anomalously weak mixing from the equator to poleward of $40^{\circ} \mathrm{S}$. Therefore, to highlight the extent to which mixing between the tropics and mid-latitudes was unusual in 1985, the monthly Lyapunov exponents, based on both NCEP/NCAR wind fields and E39C wind fields, were averaged between the equator

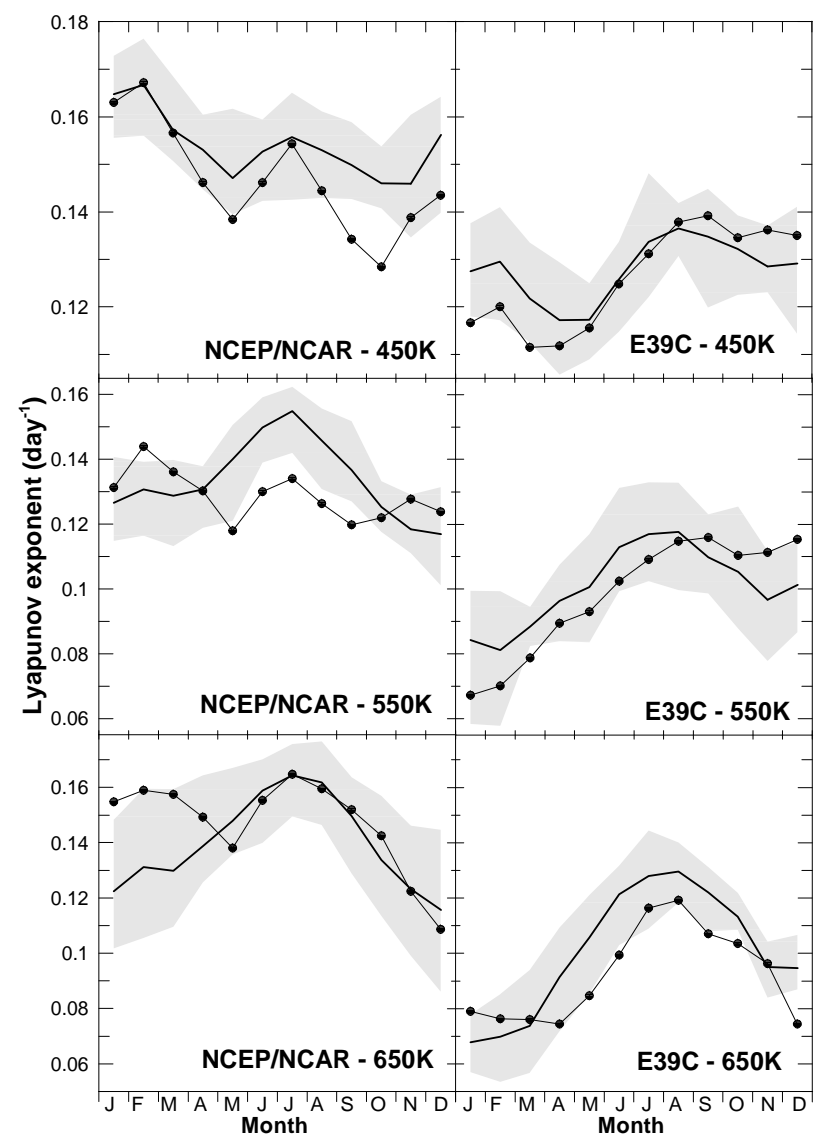

Fig. 9. Lyapunov exponents, averaged between the equator and $40^{\circ} \mathrm{S}$, for 1985 (black lines with - symbols) compared to the 1980-1989 climatology excluding 1985 (thin black line and grey shaded region showing mean, maximum and minimum), based on NCEP/NCAR wind fields (first column) and E39C wind fields, second column.

and $40^{\circ} \mathrm{S}$ for all three isentropic levels. The values for 1985 are compared with the 1980-1989 climatology (but excluding 1985) in Fig. 9. At $450 \mathrm{~K}$ the Lyapunov exponents based on NCEP/NCAR and E39C model wind fields show very different seasonal structure. In the reanalyses, highest mixing occurs in January and February (with a secondary maximum in winter) while in the E39C model, highest mixing occurs from July to September. Furthermore, the reanalyses show weaker than usual mixing through most of 1985 and particularly in September and October. In contrast, the model shows significantly weaker mixing only during the first 4 months of 1985. The sources of these differences between the reanalyses and the model are not yet clear and are the focus of ongoing analyses. At $550 \mathrm{~K}$, both the reanalyses and the model show mixing maximizing in winter (June to August), but with generally weaker mixing in the model than in the reanalyses. The reanalyses show anomalously weak mixing in 1985 from May to September while the model shows 


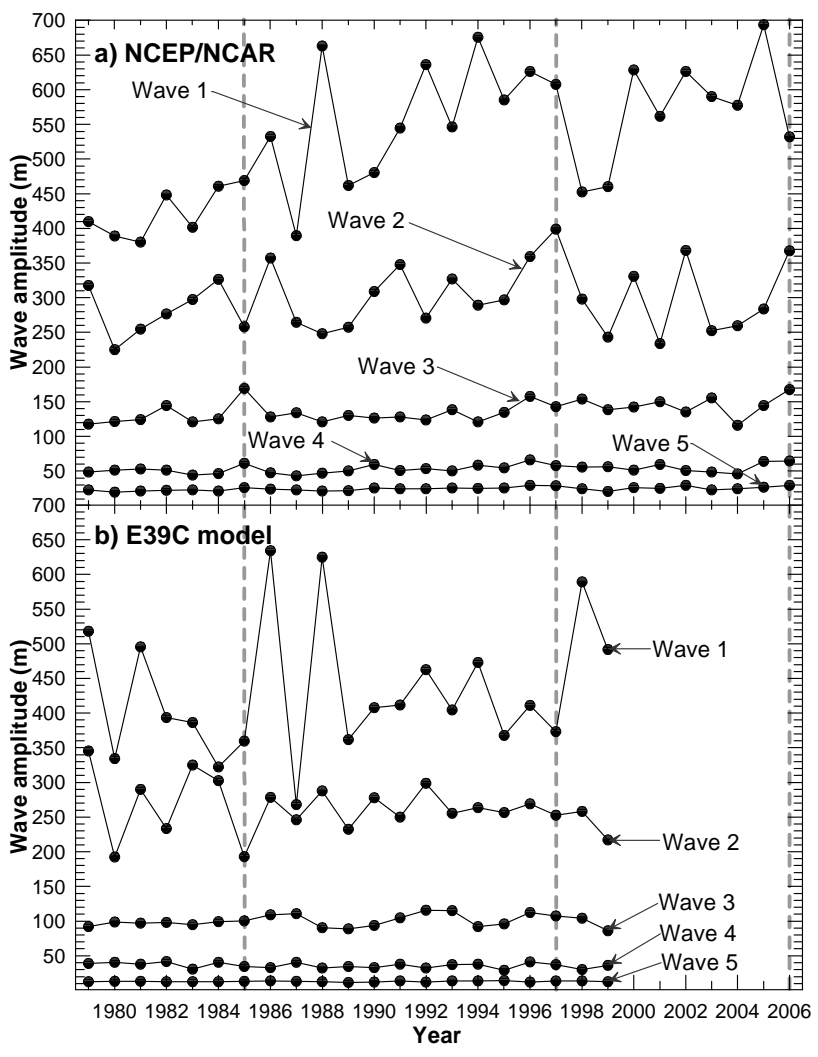

Fig. 10. $20 \mathrm{hPa}$ geopotential height wave amplitudes at $60^{\circ} \mathrm{S}$ averaged over the period 19 July to 1 December of each year for waves 1 to 5. (a) using NCEP/NCAR geopotential height fields, and (b) using E39C model geopotential height fields.

moderately weaker mixing through the first half of the year. At $650 \mathrm{~K}$, mixing also maximizes in the winter, both in the reanalyses and in the model. As at $550 \mathrm{~K}$, the equator to mid-latitude mixing in the model is weaker than in the reanalyses. While the reanalyses show no anomalously low mixing in 1985 at $650 \mathrm{~K}$, the model does show weaker mixing through much of the middle of the year. Therefore, while both reanalyses and model show a mixing anomaly in 1985, the anomaly occurs at higher altitudes in the model than in the NCEP/NCAR reanalyses.

\subsection{Associated anomalies in wave forcing}

Since mixing in the mid-latitude surf zone is driven primarily by planetary scale wave breaking, it is natural to consider whether planetary wave activity in 1985 was anomalous. To this end daily $20 \mathrm{hPa}$ geopotential height wave amplitudes at $60^{\circ} \mathrm{S}$ have been calculated from NCEP/NCAR fields and from $20 \mathrm{hPa}$ geopotential height fields extracted from the E39C model. A discrete Fourier transform was used to calculate the wave amplitudes for zonal waves 1 to 5 . Winter-time (mid-July to the end of November) means of these wave amplitudes are plotted in Fig. 10.

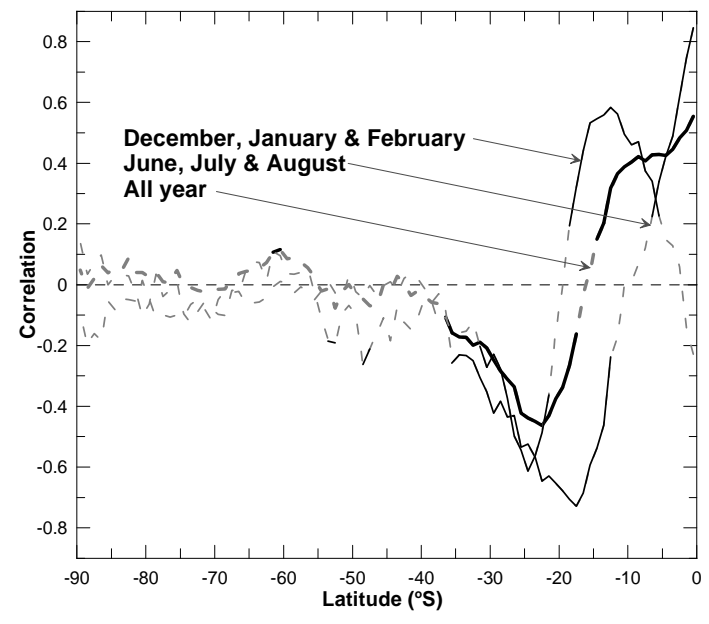

Fig. 11. The correlation between the zonal mean $550 \mathrm{~K}$ Lyapunov exponents and the $50 \mathrm{hPa}$ QBO signal as a function of latitude from 1979 to 2005 . Dashed lines show where the correlations are not statistically significant at the $95 \%$ confidence level while solid lines show where the correlations are statistically significant at the $95 \%$ confidence level.

There is no clear pattern in wave behaviour that differentiates the years of 1985, 1997 and 2006. This is true for the data plotted in Fig. 10 as well as the root sum squares of the wave amplitudes, ratios of wave amplitudes, and probability distribution functions of wave amplitudes (not shown). The year of highest wave 3 amplitude is 1985 and the second highest is 2006, but 1997 does not show anomalous wave 3 activity. Thus the only conclusion that can be drawn from Fig. 10 is that there is no specific pattern of wave activity that is responsible for the anomalous mixing in those years. The increasing wave 1 amplitudes in the NCEP/NCAR $20 \mathrm{hPa}$ geopotential height fields suggest that mixing in the southern mid-latitude surf zone should have increased over this period. Garny et al. (2007) report increasing mixing on the $450 \mathrm{~K}$ isentrope through much of the mid-latitudes of the Southern Hemisphere from 1979 to 2005. The E39C wave 1 amplitudes show a much weaker positive trend, if any, from 1979 to 1999.

\section{Discussion}

A number of lines of evidence were presented above which provide clues as to the origin of the 1985 southern midlatitude total column ozone anomaly with indications that the same mechanisms were responsible for reduced southern mid-latitude ozone in 1997 and 2006. A discussion of this evidence and the conclusions drawn are presented below.

The spatial pattern of seasonal ozone anomalies in 1985 (see Fig. 4) was evocative of QBO influence. The fact that the E39C coupled chemistry-climate model, whose equatorial winds are nudged towards observed winds, was able to 

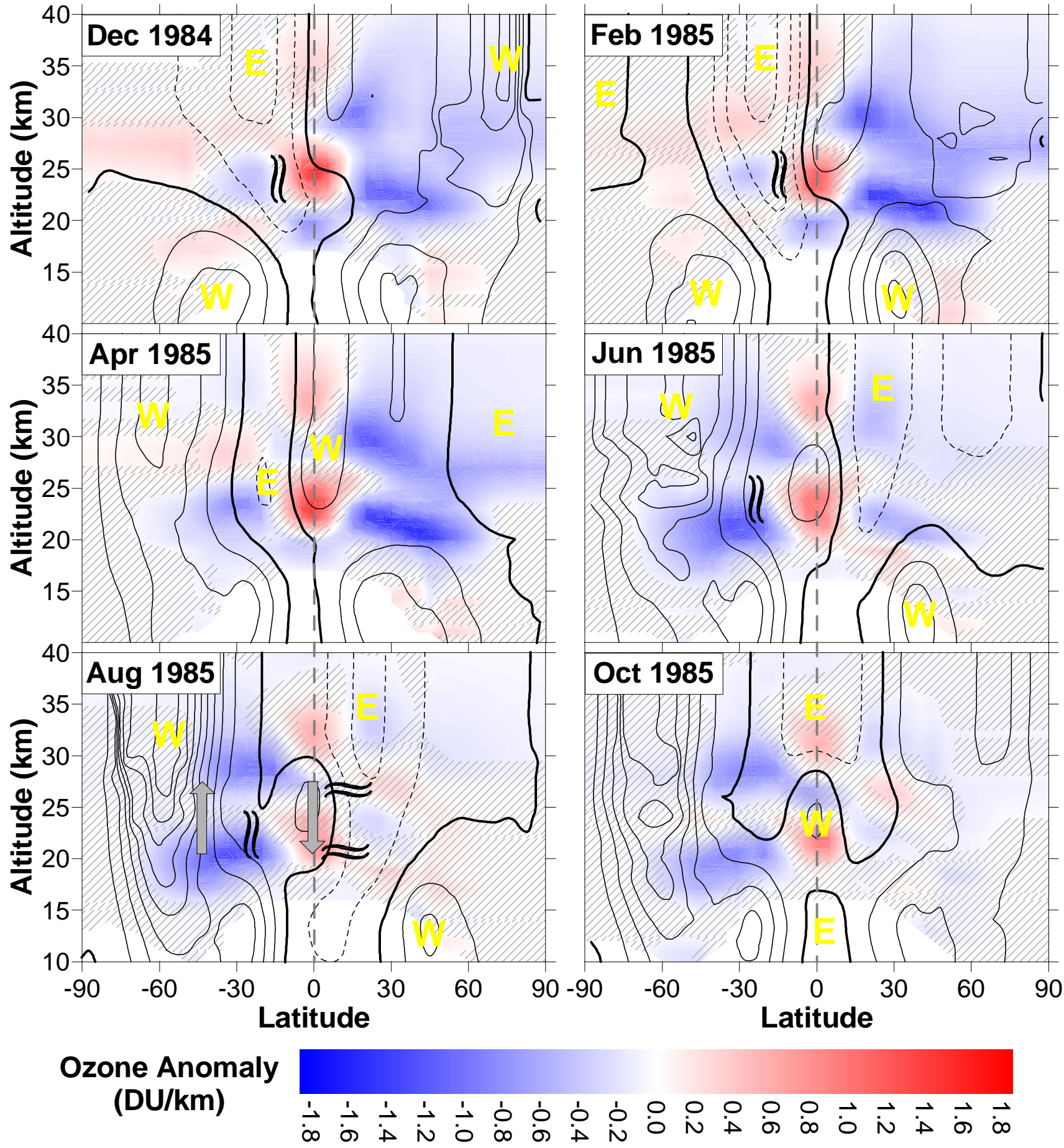

Fig. 12. Monthly mean zonal mean ozone number density anomalies shown using the colour scale at the bottom of the figure, and monthly mean zonal mean zonal wind superimposed as a contour plot (the thick solid contour shows the zero wind line; easterly winds are shown in dashed contours and westerly winds in solid contours; contour spacing is $10 \mathrm{~m} / \mathrm{s}$ ) for December 1984 and February, April, June, August, and October 1985. Yellow letters aid the identification of regions of easterly and westerly winds. Diagonally hatched regions show where the ozone anomalies are not statistically significantly different $(<1 \sigma)$ from what would be expected from stratospheric halogen loading alone. The vertical dashed line shows the equator. The white region towards the bottom center of each panel results from insufficient ozone data being available. In the bottom left panel the grey arrows show the perturbation to the Brewer-Dobson circulation i.e. a weakening of the Brewer-Dobson circulation which is anti-clockwise in the Southern Hemisphere in this panel, and using the $\approx$ symbols, the regions where planetary wave breaking at the zero wind line might cause enhanced transport out of the tropics and into mid-latitudes. The vertical $\approx$ symbols show regions of inhibited meridional mixing inferred from Fig. 11. 
Table 1. Years in which the QBO changed phase from easterly to westerly in March, April or May, together with information on the state of the solar cycle in that year.

\begin{tabular}{ccc}
\hline Year & Last month of easterlies & Solar cycle \\
\hline 1985 & March & Minimum \\
1990 & May & Maximum \\
1997 & April & Minimum \\
1999 & March & Intermediate \\
2004 & March & Intermediate \\
2006 & May & Minimum \\
\hline
\end{tabular}

capture many of the characteristics of the ozone anomaly, suggests that the QBO played a key role in forcing the anomaly. The mechanism by which the QBO modulates stratospheric ozone is well known (Kinnersley and Tung, 1999; Baldwin et al., 2001). The classical picture is of two cells on either side of the equator, with anomalous descent in the stratosphere over the tropics in the QBO westerly phase which increases ozone, and anomalous ascent in the stratosphere over the sub-tropics which decreases ozone. In QBO easterly phases, tropical ozone is reduced and sub-tropical ozone is increased (Gray and Dunkerton, 1990). In addition, there is a robust seasonal synchronization of the QBO signal resulting from seasonality in the vertical velocity of the meridional circulation which is modulated by the QBO at low and middle latitudes, and the seasonality of the planetary wave modulated circulation at high latitudes (Kinnersley and Tung, 1999). The 1985 anomaly coincided with anomalously weak mixing between the tropics and mid-latitudes in winter and spring at the 450 and $550 \mathrm{~K}$ levels (see Fig. 9). The sub-tropical barrier to meridional mixing (Trepte and Hitchman, 1992; Plumb, 1996) is not impermeable (Hu and Pierrehumbert, 2001) and large wave events transport atmospheric constituents across the barrier (Randel et al., 1993). In southern mid-latitudes, a large fraction of the ozone originates in the tropical middle stratosphere, more so in winter than in summer (Grewe, 2006). Therefore, any perturbations to the mixing across the barrier are likely to affect ozone levels over southern mid-latitudes. In general the E39C model is able to reproduce the observed climatological mean annual cycle in mixing but with lower Lyapunov exponents on average. However, these lower Lyapunov exponents may result from the coarser grid spacing of the E39C model compared to the NCEP/NCAR reanalyses (Hu and Pierrehumbert, 2001). The QBO also has a role to play in stratospheric mixing as it modulates the vertical propagation of planetary waves in the mid-latitudes (Holton and Tan, 1980; Dameris and Ebel, 1990; Shindell et al., 1999). Garny et al. (2007) show that the QBO strongly modulates mixing between the tropics and mid-latitudes at the 450,550 and $650 \mathrm{~K}$ levels, with a clear seasonal dependence (see also Shuckburgh et al., 2001). In general, in the lower stratosphere, QBO west phases cause mixing to be enhanced around the equator, with the maximum on the summer side of the equator, from June to October, accompanied by a decrease in mixing in southern subtropics. This is shown in Fig. 11 where the correlation between the zonal mean $550 \mathrm{~K}$ Lyapunov exponents, which are now calculated from NCEP/NCAR reanalyses from 1979 to 2005 , and the $50 \mathrm{hPa}$ QBO signal are plotted. When the QBO is in a westerly phase early in the year (DJF) mixing is enhanced over most of the region equatorward of $\sim 20^{\circ} \mathrm{S}$ and reduced poleward of $\sim 20^{\circ} \mathrm{S}$. In winter (JJA), a westerly phase QBO produces an enhancement in mixing equatorward of $\sim 10^{\circ} \mathrm{S}$ together with a significant reduction in mixing poleward of this latitude.

An overview of the interplay of the mechanisms outlined above, their effect on ozone concentrations, and the importance of the seasonal timing of the switch of the QBO from easterly to westerly phase is shown in Fig. 12. The ozone concentration anomalies were calculated by regressing the ozone partial column data from Randel and Wu (2007) against equivalent effective stratospheric chlorine over the period 1979 to 2005 and subtracting the fit from the observations. NCEP/NCAR zonal mean zonal winds on pressure surfaces were transformed to height coordinates based on collocated geopotential height fields. In December 1984 and through the first three months of 1985, equatorial zonal mean zonal winds at $50 \mathrm{hPa}$ were easterly (see also Fig. 1). The direct QBO induced signal in ozone would result in increases in ozone over southern mid-latitudes during this period though the effect of the QBO at this time of the year is small (Tung and Yang, 1994). This is apparent in Fig. 12 where, at least poleward of $\sim 45^{\circ} \mathrm{S}$, weak positive ozone anomalies occur. Perhaps more important, because the zero wind line between equatorial easterlies and northern mid-latitude winter-time westerlies is located over the equator or in the low latitudes of the northern hemisphere, planetary waves would break there rather than propagating across the equator and breaking close to the southern sub-tropical barrier. This would reduce mixing across the southern sub-tropical barrier (as denoted by the vertical $\approx$ symbols in the Dec 1984 panel in Fig. 12). From April 1985 to February 1987, the $50 \mathrm{hPa}$ equatorial winds were westerly. In this phase of the QBO, and in particular in winter when the QBO effect on ozone maximizes, this would cause a suppression in ozone outside of the tropics as a result of weakened descent over southern mid-latitudes (see bottom left panel of Fig. 12). In addition, because the zero wind line between the Southern Hemisphere winter-time westerlies and easterly winds is again in the northern hemisphere (because tropical winds are now westerly) planetary waves generated in the Southern Hemisphere during winter propagate across the equator and break around the northern subtropical barrier. So again, mixing across the southern subtropical barrier is reduced (Garny et al., 2007), closing the valve on the tropical source of ozone to the mid-latitudes. In the northern hemisphere summer, the negative effect of the QBO on mid-latitude ozone is small but because mixing 
across the northern sub-tropical barrier is enhanced, positive anomalies in ozone occur. In Fig. 12 (see Aug 1985 in particular) these positive ozone anomalies are not statistically significant but appear to occur in two separated altitude regions ( $\sim 18 \mathrm{~km}$ and $\sim 26 \mathrm{~km}$ ) with a statistically significant negative ozone anomaly at $\sim 23 \mathrm{~km}$.

The phasing of the change in the QBO from easterlies to westerlies with respect to the annual cycle in wave induced mixing out of the tropics to mid-latitudes explains the dipole structure seen in Fig. 8. Years characterized by a switch from easterly $50 \mathrm{hPa}$ equatorial winds early in the year to westerly winds through the remainder of the year are listed in Table 1 together with information on the solar cycle in those years.

Both 1997 and 2006 are similar to 1985 in that the QBO changed phase from easterly to westerly early in the year and were years in solar minimum. These three years were also associated with the dipole structure in ozone across the equator shown in Fig. 8. Of course these anomalies occur on top of long-term secular changes driven by halogen catalyzed in-situ ozone depletion and export of ozone depleted air from the Antarctic stratosphere following the break-up of the vortex (Ajtic et al., 2004).

The 1985 anomaly was characterized by reduced occurrences of high ozone values rather than increased occurrences of low ozone values (see Figs. 6 and 7). The relationship between surf zone (McIntyre and Palmer, 1984) tracer PDFs and Lyapunov exponent PDFs is discussed in detail in $\mathrm{Hu}$ and Pierrehumbert (2001). Specifically they show that deviations of tracer PDFs from a Gaussian distribution result from mixing of air across transport barriers i.e. from regions where Lyapunov exponents are low. This is consistent with the PDFs shown in Figs. 6 and 7 in that the usual fat tail at high ozone values results from mixing between the tropics and mid-latitudes. In 1985 the ozone PDFs are more Gaussian in shape indicative of air that has been mostly trapped in the mid-latitude surf zone. The shift in the mode of the PDFs to lower values starting in April/May 1985 is consistent with the hemisphere wide suppression of ozone related to the QBO which switched from easterly to westerly phase around this time.

\section{Conclusions}

We conclude that the 1985 Southern Hemisphere midlatitude total column ozone anomaly most likely resulted from a combination of the QBO being in the westerly phase through most of the year which suppresses mid-latitude ozone, and the switch of the QBO from easterly to westerly phase early in the year which results in reduced mixing of ozone rich air from the tropical source region to midlatitudes. In addition, a minimum in the solar cycle further lowers ozone over southern mid-latitudes in 1985. The same mechanisms were in effect in 1997 and 2006 which were also years of reduced southern mid-latitude total column ozone.
Acknowledgements. We would like to thank W. Randel and F. Wu for access to their stratospheric ozone profile data set. We would also like to thank the Laboratory for Atmospheres at GSFC for access to SBUV and TOMS data, ESA/ESRIN for access to GOME data, NOAA for access to the SBUV data from the NOAA 9, NOAA 11 and NOAA 16 satellites, and C.-F. Shih at the National Center for Atmospheric Research and the National Centers for Environmental Prediction for the NCEP/NCAR data. We would also like to thank the WOUDC for providing total column ozone measurements from the Dobson spectrophotometer network. H. Garny was funded through the Deutsche Akademische Austauschdienst (DAAD). The work performed by the DLR was financially supported by the EC-funded project SCOUT-O3. The NIWA contribution to this study work was conducted within the FRST funded Drivers and Mitigation of Global Change programme (C01X0204).

Edited by: K. Hamilton

\section{References}

Ajtic, J., Connor, B. J., Lawrence, B. N., Bodeker, G. E., Hoppel, K. W., Rosenfield, J. E., and Heuff, D. N.: Dilution of the Antarctic ozone hole into southern midlatitudes, 1998-2000, J. Geophys. Res., 109, D17107, doi:10.1029/2003JD004500, 2004.

Baldwin, M. P., Gray, L. J., Dunkerton, T. J., Hamilton, K., Haynes, P. H., Randel, W. J., Holton, J. R., Alexander, M. J., Hirota, I., Horinouchi, T., Jones, D. B. A., Kinnersley, J. S., Marquardt, C., Sato, K., and Takahashi, M.: The quasi-biennial oscillation, Rev. Geophys., 39(2), 179-230, 2001.

Bodeker, G. E., Connor, B. J., Liley, J. B., and Matthews, W. A.: The global mass of ozone: 1978-1998, Geophys. Res. Lett., 28, 2819-2822, 2001.

Bodeker, G. E., Shiona, H., and Eskes, H.: Indicators of Antarctic ozone depletion, Atmos. Chem. Phys., 5, 2603-2615, 2005, http://www.atmos-chem-phys.net/5/2603/2005/.

Bowman, K. P.: Large-scale isentropic mixing properties of the Antarctic polar vortex from analyzed winds, J. Geophys. Res., 98(D12), 23 013-23 027, 1993.

Brühl, C. and Crutzen, P. J.: MPIC two-dimensional model, NASA Ref. Publ., 1292, 103-104, 1993.

Calisesi, Y. and Matthes, K.: The middle atmospheric ozone response to the 11-year solar cycle, Space Sci. Rev., 125, 273-286, 2006.

Connor, B. J., Bodeker, G. E., McKenzie, R. L., and Boyd, I. S.: The total ozone anomaly at Lauder, NZ in 1997, Geophys. Res. Lett., 26, 189-192, 1999.

Dameris, M. and Ebel, A.: The quasi-biennial oscillation and major stratospheric warmings: A three-dimensional model study, Ann. Geophys., 8, 79-86, 1990,

http://www.ann-geophys.net/8/79/1990/.

Dameris, M., Grewe, V., Ponater, M., Deckert, R., Eyring, V., Mager, F., Matthes, S., Schnadt, C., Stenke, A., Steil, B., Brühl, C., and Giorgetta, M. A.: Long-term changes and variability in a transient simulation with a chemistry-climate model employing realistic forcing, Atmos. Chem. Phys., 5, 2121-2145, 2005, http://www.atmos-chem-phys.net/5/2121/2005/. 
Dameris, M., Matthes, S., Deckert, R., Grewe, V., and Ponater, M.: Solar cycle effect delays onset of ozone recovery, Geophys. Res. Lett., 33, L03806, doi:10.1029/2005GL024741, 2006.

Daniel, J. S., Solomon, S., and Albritton, D. L.: On the evaluation of halocarbon radiative forcing and global warming potentials, J. Geophys. Res., 100, 1271-1285, 1995.

Donnelly, R. F.: Solar UV spectral irradiance variations, J. Geomagn. Geoelectr., 43, 835-842, 1991.

Garny, H., Bodeker, G. E., and Dameris, M.: Trends and variability in stratospheric mixing: 1979-2005, Atmos. Chem. Phys., 7, 5611-5624, 2007,

http://www.atmos-chem-phys.net/7/5611/2007/.

Gray, L. J. and Dunkerton, T. J.: The role of the seasonal cycle in the quasi-biennial oscillation of ozone, J. Atmos. Sci., 47, 24292451, 1990.

Gray, L. J. and Pyle, J. A.: A two-dimensional model of the quasibiennial oscillation of ozone, J. Atmos. Sci., 46, 203-220, 1989.

Grewe, V.: The origin of ozone, Atmos. Chem. Phys., 6, 1495-1511, 2006 , http://www.atmos-chem-phys.net/6/1495/2006/.

Holton, J. R. and Tan, H.-C.: The influence of the quasi-biennial osciallation on the global circulation at $50 \mathrm{mb}$, J. Atmos. Sci., 37, 2200-2208, 1980.

$\mathrm{Hu}, \mathrm{Y}$. and Pierrehumbert, R. T.: The AdvectionDiffusion Problem for Stratospheric Flow. Part I: Concentration Probability Distribution Function, J. Atmos. Sci., 58, 1493-1510, 2001.

Huck, P. E., McDonald, A. J., Bodeker, G. E., and Struthers, H.: Interannual variability in Antarctic ozone depletion controlled by planetary waves and polar temperature, Geophys. Res. Lett., 32, L13819, doi:10.1029/2005GL022943, 2005.

Kalnay, E., Kanamitsu, M., Kistler, R., Collins, W., Deaven, D., Gandin, L., Iredell, M., Saha, S., White, G., Woollen, J., Zhu, Y., Leetmaa, A., Reynolds, B., Chelliah, M., Ebisuzaki, W., Higgins, W., Janowiak, J., Mo, K. C., Ropelewski, C., Wang, J., Jenne, R., and Joseph, D.: The NCEP/NCAR 40-Year Reanalysis Project, Bull. Am. Soc., 77(3), 437-472, 1996.

Kinnersley, J. S. and Tung, K.-K.: Modeling the global interannual variability of ozone due to the equatorial QBO and to extratropical planetary wave variability, J. Atmos. Sci., 55, 1417-1428, 1998.

Kinnersley, J. S.: Seasonal Asymmetry of the Low- and MiddleLatitude QBO Circulation Anomaly, J. Atmos. Sci., 56, 11401153, 1999.

Kinnersley, J. S. and Tung, K. K.: Mechanisms for the extratropical QBO in circulation and ozone, J. Atmos. Sci., 56, 1942-1962, 1999.

Kistler, R., Kalnay, E., Collins, W., Saha, S., White, G., Woollen, J., Chelliah, M., Ebisuzaki, W., Kanamitsu, M., Kousky, V., van den Dool, H., Jenne, R., and Fiorino, M.: The NCEPNCAR 50Year Reanalysis: Monthly Means CDROM and Documentation, Bull. Am. Soc., 82(2), 247-267, 2001.

Lait, L. R., Schoeberl, M. R., and Newman, P. A.: Quasi-biennial modulation of the Antarctic ozone depletion, J. Geophys. Res., 94, 11 559-11 571, 1989.

Lean, J., Rottmann, G., Kyle, H., Woods, T., Hickey, J., and Puga, L.: Detection and parameterisation of variations in solar midand near-ultraviolet radiation (200-400 nm), J. Geophys. Res., 102, 29 939-29 956, 1997.

Lee, H. and Smith, A. K.: Simulation of the combined effects of solar cycle, quasi-biennial oscillation, and volcanic forcing on stratospheric ozone changes in recent decades, J. Geophys. Res., 108, 4049, doi:10.1029/2001JD001503, 2003.

McCormack, J. P. and Hood L. L.: Apparent solar cycle variations of upper stratospheric ozone and temperature: latitude and seasonal dependences, J. Geophys. Res., 101, 20 933-20 944, 1996.

McIntyre, M. E. and Palmer, T. N.: The 'surf zone' in the stratosphere, J. Atmos. Terr. Phys., 46(9), 825-849, 1984.

Pierrehumbert, R. T. and Yang, H.: Global Chaotic Mixing on Isentropic Surfaces, J. Atmos. Sci., 50, 2462-2480, 1993.

Plumb, R. A.: A “tropical pipe" model of stratospheric transport, J. Geophys. Res., 101, 3957-3972, 1996.

Preisendorfer, R. W.: Principal Component Analysis in Meteorology and Oceanography, Series: Developments in atmospheric science 17, edited by: Mobley, C., Elsevier, 1988.

Press, W. H., Flannery, B. R., Teukolsky, S. A., and Vettering, W. T.: Numerical Recipes in Pascal, 759 pp., Cambridge Univ. Press, New York, 1989.

Randel, W. J., Gille, J. C., Roche, A. E., Kumer, J. B., Mergenthaler, J. L., Waters, J. W., Fishbein, E. F., and Lahoz, W. A.: Stratospheric transport from the tropics to middle latitudes by planetary-wave mixing, Nature, 365, 533-535, 1993.

Randel, W. J. and Cobb, J. B.: Coherent variations of monthly mean total ozone and lower stratospheric temperature, J. Geophys. Res., 99, 5433-5447, 1994.

Randel, W. J. and Wu, F.: A stratospheric ozone profile data set for 1979-2005: Variability, trends, and comparisons with column ozone data, J. Geophys. Res., 112, D06313, doi:10.1029/2006JD007339, 2007.

Rayner, N. A., Parker, D. E., Horton, E. B., Folland, C. K., Alexander, L. V., Rowell, D. P., Kent, E. C., and Kaplan, A.: Global analyses of sea surface temperatures, sea ice, and night marine air temperature since the late nineteenth century, J. Geophys. Res., 108, 4407, doi:10.1029/2002JD002670, 2003.

Shindell, D. T., Rind, D., and Balachandran, N.: Interannual variability of the Antarctic ozone hole in a GCM. Part II: a comparison of unforced and QBO-induced variability, J. Atmos. Sci., 56, 1873-1874, 1999.

Soukharev, B. E. and Hood, L. L.: Solar cycle variation of stratospheric ozone: Multiple regression analysis of long-term satellite data sets and comparisons with models, J. Geophys. Res., 111, D20314, doi:10.1029/2006JD007107, 2006.

Steinbrecht, W., Claude, H., Schönenborn, F., McDermid, I. S., Leblanc, T., Godin, S., Song, T., Swart, D. P. J., Meijer, Y., Bodeker, G. E., Connor, B. J., Kämpfer, N., Hocke, K., Calisesi, Y., Schneider, N., de la Nöe, J., Parrish, A. D., Boyd, I. S., Brühl, C., Steil, B., Giorgetta, M. A., Manzini, E., Thomason, L. W., Zawodny, J. M., McCormick, M. P., Russell III, J. M., Bhartia, P. K., Stolarski, R. S., and Hollandsworth-Frith, S. M.: Long-term evolution of upper stratospheric ozone at selected stations of the Network for the Detection of Stratospheric Change (NDSC), J. Geophys. Res., 111, D10308, doi:10.1029/2005JD006454, 2006.

Shuckburgh, E., Norton, W., Iwi, A., and Haynes, P.: Influence of the quasi-biennial oscillation on isentropic transport and mixing in the tropics and subtropics, J. Geophys. Res., 106, 1432714337, 2001.

Trepte, C. R. and Hitchman, M. H.: Tropical stratospheric circulation deduced from satellite aerosol data, Nature, 355, 626-628, 1992. 
Tung, K. K. and Yang, H.: Global QBO in circulation and ozone. Part II: a simple mechanistic model, J. Atmos. Sci., 51, 27082721, 1994.

WMO (World Meteorological Organisation): Scientific Assessment of Ozone Depletion: 2006, Global Ozone Research and Monitoring Project, Report No. 50, 572 pp., Geneva, 2007.
Wolf, A., Swift, J. B., Swinney, H. L., and Vastano, J. A.: Determining Lyapunov exponents from a time series, Physica D, 16, 285-317, 1985. 